\title{
A MODEL OF AMACRINE AND GANGLION CELLS FOR OPTICAL INFORMATION PROCESSING
}

\author{
A. González-Marcos(*) \& J.A. Martín-Pereda(**) \\ (*) Departamento de Automática \\ UNIVERSIDAD DE ALCALÁ DE HENARES \\ 28871 ALCALA DE HENARES. MADRID. SPAIN \\ $\left({ }^{* *}\right)$ E.T.S. Ingenieros Telecomunicación \\ UNIVERSIDAD POLITÉCNICA DE MADRID \\ 28040 MADRID. SPAIN
}

Ganglion cells differ from all other types of retinal interneurons, except the amacrines, in that they respond to light with repetitive spike discharges. Like bipolars, ganglion cells often have receptive fields consisting of a centre region with an antagonistic surround, many of them having in addition the property that they respond only transiently when retinal illumination is suddenly changed from one level to another. Sometimes a transient burst of firing is found in response to an increase of illuminations (an 'on-response'), and sometimes to a decrease ('off-response'): and sometimes one may find a burst response both at the beginning and end of a period of steady illumination (an 'on-off response'). A cell with an on-response at its centre will normally show an offresponse in its surround, and viceversa and they show on-off responses in intermediate regions. The difference with respect to bipolar cells is the result of feedback inhibition from the amacrines, whose responses are very similar to those of ganglion cells and have the right sort of connections for mediating lateral and self-inhibition of the type that would explain the time-course of the ganglion cell responses.

Several approaches have been published in the last years concerning the modelling of the retinal operation. Most of them present simple neurons with just two different responses, namely inhibitory and excitatory. Some of the different types of retinal cells are simulated in these configurations.

Another approach is going to be reported in this paper. Based on a previously reported logic cell structure [1]-[2], the two types of cells present at the inner and ganglion cell layers of the vertebrate retina and their intracellular response, as well as their connections with each other, have been simulated. These cells are amacrines and ganglion cells. The main scheme of our configuration is shown in Fig. 1. These two types of cells, as well as some of their possible interconnections, have been implemented with our previously reported Optical-Processing Element (OPE) [1]-[2].

As it has been shown, our logic structure is able to process two optical input binary signals, being the output two logical functions. Moreover, if a delayed feedback from one of the two possible outputs to one or both of the inputs is introduced, a very different behaviour is obtained. Depending on the value of the time delay, an oscillatory output can be obtained from a constant optical input signal. Period and length pulses are depending on delay values, both external and internal, as well as on other control signals. Moreover, a chaotic behaviour can be obtained too under certain conditions.

With above facts, a part of the configuration previously proposed by us [3] to 
summarize the activity of the various retinal layers, has been studied in this work. The main objective of the present work has been to obtain a new Optical-Processing Structure with a behaviour as much similar to the one held by ganglion cells as possible. Several configurations have been implemented in order to simulate such a behaviour. One of them is shown in Fig. 1. G1, G2 and G3 are ganglion cells. $S_{1}, S_{2}, S_{3}$ and $S^{4}$ are the corresponding synapsis between ganglion cells and amacrine. Arrows indicate signal paths. As it is possible to see, optical signals coming out from this structure are the result of the different signals from higher levels. 'On', 'off' and 'on-off' responses have been obtained under different input conditions. No attempt has been given to the study of higher layers. A general model, with a more simplified behaviour, has been reported previously. Some information about these layers has been reported there. Because the behaviour of structure we have employed is based on comparison between two signals, it can perform similar functions with different light levels.

Our work has been mainly carried out by computer simulation although an optoelectronic implementation, for a single OPE type, has been achieved. Multimode optical fibers, as link between cells, have been employed as signal carrier. Light was generated from LED and pin diodes were acting as detectors. Signal processing, inside each OPE has been carried out by electronic circuitry.

With this configuration, information about where the initial light has impinged onto the system is detected from the type of signals going out from ganglion cells. Possible extensions to higher order architectures will be reported. These new configurations will allow to process other types of information, as motion, edge detection and direction.

\section{REFERENCES}

[1] González-Marcos, A. \& J.A. Martín-Pereda. "Quasi-chaotic digital behaviour in an optically processing element". SPIE, 2038, 67-77. (1993).

[2] J.A. Martín-Pereda \& A. González-Marcos. "Optical Programmable Processing Element using Optical Fibers". IEEE Lasers and Electro-Optics Society, LEOS'92. Boston, 15-20 November, 1992.

[3] J.A. Martín-Pereda \& A. González-Marcos. "An Approach to Visual Cortex Operation: Optical Neuron Model". CLEO/Europe-EQEC'94. Amsterdam, 28 August-2 September, 1994. 